\title{
Integration of protein context improves protein- based COVID-19 patient stratification
}

\author{
Jinlong Gao \\ Westlake University \\ Jiale He \\ Westlake University \\ Fangfei Zhang \\ Westlake University \\ Qi Xiao \\ Westlake University \\ Xue Cai \\ Westlake University \\ Xiao Yi \\ Westlake University \\ Siqi Zheng \\ Westlake University \\ Ying Zhang \\ Taizhou Hospital, Wenzhou Medical University \\ Donglian Wang \\ Taizhou Hospital, Wenzhou Medical University \\ Guangjun Zhu \\ Taizhou Hospital, Wenzhou Medical University \\ Jing Wang \\ Taizhou Hospital, Wenzhou Medical University

\section{Bo Shen} \\ Taizhou Hospital, Wenzhou Medical University

\section{Markus Ralser} \\ The Francis Crick Institute \\ Tiannan Guo ( $\square$ guotiannan@westlake.edu.cn ) \\ Westlake University \\ Yi Zhu \\ Westlake University
}


Keywords: COVID-19, Severe cases, Proteomics, Protein complex, Stoichiometric ratio

Posted Date: February 7th, 2022

DOI: https://doi.org/10.21203/rs.3.rs-1325253/v1

License: (c) (1) This work is licensed under a Creative Commons Attribution 4.0 International License. Read Full License 


\section{Abstract}

Background: Classification of disease severity is crucial for the management of COVID-19. Several studies have shown that individual proteins can be used to classify the severity of COVID-19. Here, we aimed to investigate whether integrating the four types of protein context data, namely, protein complexes, stoichiometric ratios, pathways and network degrees will improve the severity classification of COVID-19.

Methods: A SWATH-based proteomic data set of 54 sera samples from 40 COVID-19 patients was employed as the training cohort.

Results: Machine learning prioritized two complexes, one stoichiometric ratio, five pathways, twelve proteins and five network degrees. A model based on these 25 features led to effective classification of severe cases with an AUC of 0.965 , outperforming the models with proteins only. Complement component C9, transthyretin (TTR) and TTR-RBP complex, the stoichiometric ratio of SAA2/ YLPM1, and the network extent of SIRT7 and A2M were highlighted in this classifier. This classifier was further validated with a TMT-based proteomic data set from the same cohort and an independent SWATH-based proteomic data set from Germany, reaching an AUC of 0.900 and 0.908 , respectively. Machine learning models integrating protein context information achieved higher AUCs than models with only one feature type.

Conclusion: Our results show that the integration of protein context including protein complexes, stoichiometric ratios, pathways, network degrees, and proteins improves phenotype prediction.

\section{Background}

COVID-19 caused by SARS-CoV-2 remains an ongoing pandemic ${ }^{1}$. Distinguishing severe and non-severe cases is crucial since only the severe cases require special medications such as artificial ventilation ${ }^{2}$. Proteins from COVID-19 patients' serum or plasma have been utilized to develop severity classifiers. In a TMT-based serum proteomics and metabolomics study, 118 sera samples from 65 COVID-19 patients and 53 controls were analyzed, resulting in a classifier based on characteristic proteins and metabolites ${ }^{3}$. A longitudinal cohort from hospitalized COVID-19 patients identified a distinct proteomic trajectory associated with mortality in blood samples ${ }^{4}$. Another longitudinal cohort established an immune biomarker panel to gauge the severity of COVID-19 ${ }^{5}$. Mao et al. revealed the characteristics monitoring recovered COVID-19 patients based on plasma proteomics ${ }^{6}$. Demichev et al. presented a prognostic map of COVID-19 by linking clinical parameters to plasma proteomes ${ }^{7}$ and established a proteomic survival predictor to distinguish severe cases $^{8}$.

However, the protein classifiers for COVID-19 patients mentioned above is based on individual biomolecules, mainly proteins, ignoring the fact that no protein functions in an isolated manner. As the ultimate effectors of diseases, protein complexes regulate many core biological processes. For example, 
mitochondrial complexes, such as the mitochondrial ribosomal small subunit, respiratory chain complex I and the mitochondrial pyruvate dehydrogenase complex, are involved in energy production and found to be highly conserved but dysregulated in diseases such as cancers ${ }^{9}$. Several tools for analyzing the protein complex features have been reported in recent years, including NetProt and Fuzzy-FishNET 10,11. PCprophet is a machine learning based software for identifying protein complex ${ }^{12}$. Protein stoichiometric ratios in a complex are also important since they are self-normalized and relatively conserved ${ }^{13}$. In addition, protein network degree is the number of edges connected to a protein in a network that includes all proteins in the matrix. The degree of the network transcends the expression level of the protein and reveals co-expression associations with other proteins ${ }^{14}$. In a cellular model, 332 high-confidence protein-protein interactions between SARS-CoV-2 and host proteins were identified using affinity purification mass spectrometry ${ }^{15}$. However, this study is limited to the cellular model, and it is hence not directly transferrable to human plasma collected from patients with COVID-19.

In this study, we evaluated the feasibility to utilize protein context information, including protein complexes, stoichiometric ratios in a complex, protein pathways and degree of protein networks, besides proteins, as key features to classify severe COVID-19 cases using machine learning. We developed a classifier using a training cohort consisting of 54 sera samples from 40 COVID-19 patients. Subsequently, its performance was evaluated in two independent test sets. The results showed that protein context could be exploited as integrative biomarkers for the stratification of COVID-19.

\section{Methods}

\section{Patients and datasets}

The training set for this study consisted of 54 sera samples from 40 Chinese COVID-19 patients ( 25 nonsevere and 15 severe, according to the Chinese Government Diagnosis and Treatment Guideline 5th version), quantified using SWATH-MS based proteomics. Its performance was subsequently evaluated in two test datasets. One was a TMTpro 16 plex dataset from our previous publication ${ }^{3}$, containing 21 samples from 21 patients ( 6 non-severe and 15 severe). Another was the SWATH-MS data set of 102 sera samples from 31 German patients ${ }^{16}$.

\section{Mass spectrometry data acquisition}

For the SWATH-MS experiment, Eksigent NanoLC 400 System (Eksigent, Dublin, CA, USA) and TripleTOF 5600 system (SCIEX, CA, USA) were used. Peptides were separated at a flow rate of $5 \mu \mathrm{L} / \mathrm{min}$ with a 20 min gradient ( $5 \%-30 \%$ buffer B) by an analytical column ( $3 \mu \mathrm{m}$, ChromXP C18CL, $120 \mathrm{~A}, 150 * 0.3 \mathrm{~mm})$. The acquisition range for the TOF-MS scan was 350-1250 Th with an ion accumulation time of $250 \mathrm{ms,}$ while the mass tolerance for MS/MS scans was $50 \mathrm{ppm}$ with an ion accumulation time of $50 \mathrm{~ms}$. SWATH-MS data were analyzed using OpenSWATH (version 2.4.0). The retention time was calibrated using common internal Retention Time standards (CiRT) peptides with $\mathrm{m} / \mathrm{z}$ extraction of $50 \mathrm{ppm}$ tolerance. Peptide precursors were identified by PyProphet with an FDR $<0.01$ at both the peptide and 
protein levels using a self-built spectral library containing 3287 peptide precursors from 537 protein

groups. The TMT method was described in our previous paper ${ }^{3}$. The German cohort protein data matrix has been described previously ${ }^{16}$.

\section{Enrichment of protein complexes and pathways for machine learning model}

Complexes were enriched from CORUM ${ }^{17}$ and BioPlex Explorer $3.0^{18}$ using all identified proteins in the training cohort. Differential proteins were filtered by R package Limma (version 3.44) by fitting a linear model and calculating a $\mathrm{p}$ value $(<0.05)$. The $\mathrm{GO}$ pathways and their proteins were discovered by G:profiler (version e99_eg46_p14_f929183, database updated on 07/02/2020) (adjust p value <0.05) from the proteins in the training cohort. Differential proteins were used to enrich pathways from BioPlex Explorer 3.0 (adjust $p$ value < 0.001). The values for complexes and pathways were the sum of the Zscore of proteins in complexes and pathways. The values of the stoichiometric ratios were the division of raw signals of two proteins in a complex. The differential complexes, stoichiometric ratios and pathways were filtered by R package Limma (version 3.44) ( $p$ value $<0.05$ ). The Random Forest machine learning model was based on an R package random forest (version 4.6-14) with 5000 trees and 5 nodes as the minimum size of terminal nodes, while the type of prediction was chosen to be probabilistic. Ten-fold cross validation was performed for each training process of the machine learning model. Receiver Operator Curve (ROC) was estimated by predicting results of the cross-validation using R package pROC (version 1.15.3).

\section{Generation of network degree features}

For a proteomic data set containing $\mathrm{m}$ proteins and $\mathrm{n}$ samples, $\mathrm{n}$ sample-specific networks (SSN) corresponding to the $\mathrm{n}$ samples were created from the original protein expression matrix. There will be $\mathrm{m}$ nodes corresponding to $\mathrm{m}$ proteins in each $\mathrm{SSN}$. The edges are the protein-protein expression associations without direction. Subsequently, a network degree matrix (NDM) with the same number of rows and columns as the original protein expression matrix was transformed from SSNs. Each row of the NDM is a network degree feature reflecting the importance of the protein in the network.

\section{Data visualization}

UMAPs were plotted by R package UMAP (version 0.2.5.0). Heatmaps were plotted by R package heatmap (version 1.0.12). Density plots were performed by Kernel Density Estimation, a base function of R (version 4.0.0) (a Gaussian kernel with default bandwidth was used).

\section{Results}

\section{Three sera proteomics data sets for modeling and testing}

Three independently obtained proteomic data sets of sera from COVID-19 patients were utilized in this study (Figure 1). The training data set was a matrix containing the relative expression of 331 proteins in 
54 sera samples from 40 patients ( 25 non-severe and 15 severe) with $21.7 \%$ missing values. The mean age of the patients was 51.1 years and the mean body mass index (BMI) was 23.9. Severe patients exhibited a higher BMI $(P<0.01)$ and a higher incidence of hypertension and diabetes than the nonsevere cases (Table 1 and Table S1). In addition, two test datasets were included. The first is the TMTpro 16 plex data set from our previous publication ${ }^{3}$, containing a relative expression of 894 proteins in 21 sera samples from 21 patients ( 6 non-severe and 15 severe). The other is a 5-minute gradient SWATH data containing the relative expression of 222 proteins in 102 sera samples from 31 German patients with $12.2 \%$ missing values ${ }^{16}$. The details of the protein matrix are summarized in Table 2.

\section{Extraction of protein context features}

We established a few protein context features including protein complexes, protein stoichiometric ratios in a protein complex, pathways, proteins and network degrees. A total of 868 features were obtained based on the quantification of 331 proteins (Table S2). For protein complexes, two databases, namely BioPlex and CORUM, were utilized to retrieve the complex entities based on the 331 proteins. This led to identification of 27 potentially functional protein complexes from BioPlex, a database of human proteinprotein interactions based on affinity purification mass spectrometry (AP-MS) ${ }^{18}$. In addition, 16 protein complexes were identified from the CORUM database, a manually curated and experimentally characterized protein complexes repository ${ }^{17}$. Therefore, BioPlex and CORUM together led to 43 protein complexes (Table S3). For each protein complex, we computed the ratio of each protein pair, leading to 105 protein ratios (Table S3). Subsequently, 58 pathway features were enriched by 71 differentially expressed proteins (Limma, adjust $p<0.05$ ) between severe and non-severe patients by G:profiler ${ }^{19}$. Thus, we compiled a feature list containing 43 complexes, 71 differentially expressed proteins and 58 enriched pathways (Table S3), which were utilized as input features for machine learning to stratify COVID-19 patients. Additionally, protein network degrees, which reveal the co-expression relationships with other proteins ${ }^{14}$, were also applied as one type of feature. A total of 331 protein degrees were obtained as features (Table S2). Finally, we focused on differential features between severe and nonsevere patients using limma ( $P$ value $<0.05)$. A total of 192 differential features were obtained, including 7 complexes, 16 protein stoichiometry ratios, 27 pathways, 71 proteins, and 71 protein network degrees (Table S4).

\section{Classification of severe patients using machine learning}

As shown in Figure 2A, all the 192 identified features by Limma were ranked by log-scaled $p$ values. To further identify biomarkers for the classification of severe cases, a random forest machine learning model based on the above-mentioned features was applied to the training cohort. The fit of the model was evaluated by the area under the curve (AUC) (Figure 2A). The best classifier contained the top twenty-five features, including two complexes, one stoichiometric ratio, five pathways, twelve proteins, and five network degrees (Figure 2B, S1). The changes of the top 25 features in sera of severe cases (Chinese SWATH cohort) are visualized in a heatmap (Figure 2C). 
Compared with the results using all the features, with these 25 features, severe and non-severe patients in the training set and two independent test sets can be well distinguished (Figure 3A), and the model achieved an AUC of 0.965 in the training set (Figure 3B). We next tested this model in an independent TMT-based proteomic data set containing 6 non-severe and 15 severe cases (Test set 1). The model achieved an AUC of 0.900 in this dataset (Figure 3B). It should be noted that not all the top 25 features were used in test sets due to some missing features. Actually, 18 features, including two complexes, five pathways, nine proteins, and two network degrees, were identified in the test data set 1 . Next, this classifier was further evaluated using another independent SWATH data set from 12 non-severe and 19 severe German patients (Test set 2$)^{16}$. In total, 16 features, including two complexes, five pathways, eight proteins, and one network degree were identified in the test data set 2, leading to an AUC of 0.908 (Figure 3B). The AUC results reveal that, besides proteins, protein complexes, stoichiometric ratios, pathways and protein degrees could be potential biomarkers for stratification of COVID-19 patients.

To validate whether the selected features were optimal for our classifier, we built 200 models with random features and validated them with the TMT data set and the SWATH-based German cohort dataset. The median AUC of these models is 0.756 , which is significantly lower than the AUC of the model with top 25 features $(0.900)$, indicating the superiority of our selected features.

\section{Modeling with only one type of feature}

To explore whether the machine learning models with five different types of features are superior to the models with only one type of feature, we trained models with only one type of feature and tested them with the TMT-based proteomics data set (test set 1) and the SWATH-based German cohort data set (test set 2). As shown in Figure 3B, for the training set and test set 2, the AUC values for the model with all five types of features were 0.965 and 0.908 , respectively, which were better than the AUC of the model only with proteins as the feature ( 0.949 and 0.883 , respectively). For test set 1 , the model with all types of features reached an AUC of 0.900 , which was slightly lower than that of the model only with proteins. This may be because that test set 1 is based on the TMT-tagging data acquisition mode, which is different from the SWATH data of the training data set and test set 2 . In addition, the difference in sample size may have also contributed.

The AUC for the model with only the protein network degree as features reached $0.932,0.667$, and 0.467 in the training set and the two test sets, respectively, indicating that it performs well in the training set, but not in the two test sets (Figure 3B). Similar observation was found in the model with only the protein complex ratio as a feature (Figure 3B). These findings together consolidate the benefit of integrating multiple model features for COVID-19 patient stratification.

\section{Discussion}

The highlight of this study is that we integrated five types of features including protein complexes, protein stoichiometric ratios, pathways, network degrees, and proteins, rather than using purely individual 
proteins, to build machine learning models for disease classification. Twenty-five predictive markers were identified to stratify COVID-19. Our work demonstrates that integrating protein expression levels with protein context improves COVID-19 patient stratification.

The 25 features highlighted by our analysis are all associated with the pathogenesis of COVID-19. As shown in Figure 4, after the SARS-CoV-2 enters the alveolar, the macrophages subsequently phagocytose the virus and release cytokines, resulting in the release of acute phase proteins (APPs) from the liver ${ }^{20}$. These APPs stimulate the complement system response ${ }^{21}$. However, in severe cases, the complement system reacts abnormally, which can potentially trigger a cytokine storm ${ }^{22,23}$. On one hand, cytokine storm leads to multi-organ damages, such as damages to the liver and testis ${ }^{24}$. On the other hand, more macrophages are recruited from the peripheral blood to the lungs, causing alveolar macrophage infiltration, lung damage, and respiratory failure ${ }^{25}$.

Several studies have reported predictive blood markers for severe cases, such as ITIH4 ${ }^{26,27}$, M-CSF, CCL3 and CCL4 ${ }^{28}$, as well as CMAs ${ }^{29}$. Studies utilizing MS-based proteomics also have found that proteins associated with complement system, acute phase protein response, inflammation system, macrophage dysregulation, antibody response, and coagulation system are altered in severe COVID-19 cases 3, 6, 7, 16, 30 , which have also been confirmed by other proteomic approaches ${ }^{31-33}$. In this study, we found a complex, two pathways, seven proteins and one network degree are involved in the complement system, acute phase proteins and inflammation, including "SAA1, SAA2, YLPM1", "complement activation", "acute-phase response", IGHG3, SAA1, SAA2, IGLV1-47, C9, ITIH4, C4BPA and IGHV3-73 (Figure S1). In addition, one pathway (phagocytosis, engulfment) associated with macrophage dysregulation was identified as a key feature. Our data uncovered previously hidden COVID-19-associated proteome context information.

Our study also identified other molecular features in severe patients. Several transport proteins were upregulated. Vitamin D-binding protein (GC) enhances the activity of C5a in the complement system ${ }^{34}$, which may induce cytokine storms. MyRIP, another transport protein, participates in melanosomes and produces pigmented melanin to skins ${ }^{35}$. The upregulation of MyRIP may be related to skin hyperpigmentation in severe patients ${ }^{36}$. Transthyretin (TTR) is a marker for inflammation and a negative acute-phase reactant. Reduced TTR has been reported to be associated with acute-phase response induced by inflammation, and TTR is also a malnutrition marker, suggesting nutritional disorders in severe cases ${ }^{37}$. TTR-RBP complex consists of TTR and retinol-binding protein 4 (RBP4), and the upregulation of TTR-RBP complex suggests an improved inflammation state ${ }^{38}$. In this study, both TTR and TTR-RBP complexes decreased in the sera of severe cases, suggesting a more intense acute response and inflammatory state.

Notably, some proteins associated with the complement system were also altered in severe cases. Abnormal response of complement system can trigger cytokine storm, which can further develop into severe cases ${ }^{22,39}$. Carvelli et al. found that C5 was the main effector of abnormal complement system, 
and blockade of $\mathrm{C} 5$ could prevent excessive lung inflammation ${ }^{40}$. Complement protein $\mathrm{C} 3$ was also associated with fatal outcome of COVID-19 ${ }^{23}$. Different from previous studies, we found that C9, another protein in the complement system, was elevated in severe cases, suggesting that it may also be a marker or potential therapeutic target. In addition, GC, which activates the activity of $\mathrm{C}^{3}{ }^{34}$, was also upregulated. C4BPA associated with C4 activity was abnormally expressed ${ }^{41}$ (Figure 4). In addition to changes in proteins associated with complement system, RPIA was downregulated in severe cases, which may indicate an impaired glucose metabolism and liver damage. The Tudor domain-containing protein 1 (TDRD1), which plays a central role in spermatogenesis ${ }^{42}$, was also downregulated, which may contribute to impaired testis functions observed in severe cases ${ }^{24}$.

In addition to proteins, other types of protein context feature further shed light on the mechanism of severe COVID-19 cases. Cytolysis pathway is induced after viral infection and serves as a clearance mechanism for infected cells ${ }^{43}$. The alteration of the phosphatidylcholine binding pathway may contribute to the inflammatory process ${ }^{44}$. The increased ratio of SAA2/YLPM1 in the "SAA2, SAA1, YLPM1" complex in severe cases may be due to upregulation of SAA2 (sera amyloid A-2 protein) and downregulation of YLPM1 (YLP motif-containing protein 1, Figure S1), revealing an acute-phase response and an enhanced repair of inflammation-induced telomere shortening ${ }^{45}$. The network degree changes of some proteins were associated with cytokine storm. Immunoglobulin heavy variable 3-73 (IGHV3-73) participates in antigen recognition ${ }^{46}$. MTTP stimulates phosphatidylcholine transport ${ }^{47}$. Alpha-2macroglobulin (A2M) influences cytokines signaling ${ }^{48}$, and SIRT7 suppresses inflammation ${ }^{49}$. Since network degree suggests the co-expression associations with other proteins, the network degree changes of these proteins also uncorvered systematic molecular changes in severe cases. Our study showed that the predictive result of the model with five different features was better than that of the model with one single feature (Figure 3B), suggesting the benefits of integrating multiple protein context in disease prediction and stratification.

Some limitations of this study should be noted. There were missing features in the two test sets. Seven features were not included in the TMT data, and nine features were excluded in the German cohort data. Median value of all the valued features were used to impute these missing features. The sample size of the training set is limited. Nevertheless, the model achieved satisfactory AUCs in these independent tests. Neither these limitations compromise the major conclusion of this study that integrating protein context information improves COVID-19 severity classification. Moreover, the protein complex information was obtained from cellular complexes, meaning that not all the complexes are necessarily formed in the serum, which needs to be verified by future research. Finally, building ratios may create an overfitting danger, but this can be avoided by building models with other types of features together.

\section{Conclusion}

Protein complexes, stoichiometric ratios, pathways and network degrees could be used as biomarkers to identify severe cases. Our present study confirms some of the previously reported molecular changes and 
identifies some new features that may contribute to understand the pathogenesis of COVID-19.

\section{Abbreviations}

APPs: Acute phase proteins; GC: Vitamin D-binding protein; TTR: Transthyretin; RBP4: Retinol-binding protein 4; TDRD1: Tudor domain-containing protein 1; SAA2: Sera amyloid A-2 protein; A2M: Alpha-2-2 macroglobulin; IGHV3-73: Immunoglobulin heavy variable 3-73.

\section{Declarations}

\section{Acknowledgements}

We thank the Supercomputer Center of Westlake University for its assistance in data storage and computation.

\section{Authors' contributions}

TNG and YZ designed and supervised the project. JLG summarized the pathological mechanism of severe cases and wrote the manuscript. TNG and YZ guided the writing of manuscript. JLH and FFZ organized and analyzed data. SZ designed the algorithm. QX provided suggestion for figures and manuscript. YZ, DLW, GJZ, JW and BS provided clinical guidance and sample. MR provided the test set 2 data.

\section{Funding}

This work is supported by grants from the National Key R\&D Program of China (No. 2020YFE0202200), the National Science Fund for Young Scholars (21904107), the National Natural Science Foundation of China (81972492), Zhejiang Provincial Natural Science Foundation for Distinguished Young Scholars (LR19C050001), Hangzhou Agriculture and Society Advancement Program (20190101A04), and Westlake Education Foundation, Tencent Foundation. Work in the MR lab is supported by the ERC (SyG-2020 951475) and the Wellcome Trust (IA 200829/Z/16/Z), and the specific work received funding from the Ministry of Education and Research (BMBF), as part of the National Research Node 'Mass spectrometry in Systems Medicine (MSCoresys), under grant agreements 031L0220, and Research (NaFoUniMedCOVID-19 - NUM-NAPKON, FKZ: 01KX2021).

\section{Availability of data and materials}

All data generated or analyzed during this study are included in this published article.

\section{Ethics approval and consent to participate}

This study was approved by the ethics committee of Wenzhou Medical University. All included participants provided written informed consent for the study. 


\section{Consent for publication}

Not applicable.

\section{Competing interests}

The authors declare no conflicts of interests.

\section{References}

1. Hui, D. S.; E, I. A.; Madani, T. A.; Ntoumi, F.; Kock, R.; Dar, O.; Ippolito, G.; McHugh, T. D.; Memish, Z. A.; Drosten, C.; Zumla, A.; Petersen, E., The continuing 2019-nCoV epidemic threat of novel coronaviruses to global health - The latest 2019 novel coronavirus outbreak in Wuhan, China. Int J Infect Dis 2020, 91, 264-266.

2. Gao, Y. D.; Ding, M.; Dong, X.; Zhang, J. J.; Kursat Azkur, A.; Azkur, D.; Gan, H.; Sun, Y. L.; Fu, W.; Li, W.; Liang, H. L.; Cao, Y. Y.; Yan, Q.; Cao, C.; Gao, H. Y.; Bruggen, M. C.; van de Veen, W.; Sokolowska, M.; Akdis, M.; Akdis, C. A., Risk factors for severe and critically ill COVID-19 patients: A review. Allergy 2021, 76 (2), 428-455.

3. Shen, B.; Yi, X.; Sun, Y.; Bi, X.; Du, J.; Zhang, C.; Quan, S.; Zhang, F.; Sun, R.; Qian, L.; Ge, W.; Liu, W.; Liang, S.; Chen, H.; Zhang, Y.; Li, J.; Xu, J.; He, Z.; Chen, B.; Wang, J.; Yan, H.; Zheng, Y.; Wang, D.; Zhu, J.; Kong, Z.; Kang, Z.; Liang, X.; Ding, X.; Ruan, G.; Xiang, N.; Cai, X.; Gao, H.; Li, L.; Li, S.; Xiao, Q.; Lu, T.; Zhu, Y.; Liu, H.; Chen, H.; Guo, T., Proteomic and Metabolomic Characterization of COVID-19 Patient Sera. Cell 2020.

4. Gutmann, C.; Takov, K.; Burnap, S. A.; Singh, B.; Ali, H.; Theofilatos, K.; Reed, E.; Hasman, M.; Nabeebaccus, A.; Fish, M.; McPhail, M. J.; O'Gallagher, K.; Schmidt, L. E.; Cassel, C.; Rienks, M.; Yin, X.; Auzinger, G.; Napoli, S.; Mujib, S. F.; Trovato, F.; Sanderson, B.; Merrick, B.; Niazi, U.; Saqi, M.; Dimitrakopoulou, K.; Fernandez-Leiro, R.; Braun, S.; Kronstein-Wiedemann, R.; Doores, K. J.; Edgeworth, J. D.; Shah, A. M.; Bornstein, S. R.; Tonn, T.; Hayday, A. C.; Giacca, M.; Shankar-Hari, M.; Mayr, M., SARS-CoV-2 RNAemia and proteomic trajectories inform prognostication in COVID-19 patients admitted to intensive care. Nat Commun 2021, 12 (1), 3406.

5. Laudanski, K.; Jihane, H.; Antalosky, B.; Ghani, D.; Phan, U.; Hernandez, R.; Okeke, T.; Wu, J.; Rader, D.; Susztak, K., Unbiased Analysis of Temporal Changes in Immune Serum Markers in Acute COVID-19 Infection With Emphasis on Organ Failure, Anti-Viral Treatment, and Demographic Characteristics. Front Immuno/ 2021, 12, 650465.

6. Mao, K.; Tan, Q.; Ma, Y.; Wang, S.; Zhong, H.; Liao, Y.; Huang, Q.; Xiao, W.; Xia, H.; Tan, X.; Luo, P.; Xu, J.; Long, D.; Jin, Y., Proteomics of extracellular vesicles in plasma reveals the characteristics and residual traces of COVID-19 patients without underlying diseases after 3 months of recovery. Cell Death Dis 2021, 12 (6), 541.

7. Demichev, V.; Tober-Lau, P.; Lemke, O.; Nazarenko, T.; Thibeault, C.; Whitwell, H.; Rohl, A.; Freiwald, A.;

Szyrwiel, L.; Ludwig, D.; Correia-Melo, C.; Aulakh, S. K.; Helbig, E. T.; Stubbemann, P.; Lippert, L. J.; 
Gruning, N. M.; Blyuss, O.; Vernardis, S.; White, M.; Messner, C. B.; Joannidis, M.; Sonnweber, T.; Klein, S. J.; Pizzini, A.; Wohlfarter, Y.; Sahanic, S.; Hilbe, R.; Schaefer, B.; Wagner, S.; Mittermaier, M.; Machleidt, F.; Garcia, C.; Ruwwe-Glosenkamp, C.; Lingscheid, T.; Bosquillon de Jarcy, L.; Stegemann, M. S.; Pfeiffer, M.; Jurgens, L.; Denker, S.; Zickler, D.; Enghard, P.; Zelezniak, A.; Campbell, A.; Hayward, C.; Porteous, D. J.; Marioni, R. E.; Uhrig, A.; Muller-Redetzky, H.; Zoller, H.; Loffler-Ragg, J.; Keller, M. A.; Tancevski, I.; Timms, J. F.; Zaikin, A.; Hippenstiel, S.; Ramharter, M.; Witzenrath, M.; Suttorp, N.; Lilley, K.; Mulleder, M.; Sander, L. E.; group, P.-C.-S.; Ralser, M.; Kurth, F., A time-resolved proteomic and prognostic map of COVID-19. Cell Syst 2021, 12 (8), 780-794 e7.

8. Demichev, V.; Tober-Lau, P.; Nazarenko, T.; Aulakh, S. K.; Whitwell, H.; Lemke, O.; Röhl, A.; Freiwald, A.; Mittermaier, M.; Szyrwiel, L.; Ludwig, D.; Correia-Melo, C.; Lippert, L. J.; Helbig, E. T.; Stubbemann, P.; Olk, N.; Thibeault, C.; Grüning, N.-M.; Blyuss, O.; Vernardis, S.; White, M.; Messner, C. B.; Joannidis, M.; Sonnweber, T.; Klein, S. J.; Pizzini, A.; Wohlfarter, Y.; Sahanic, S.; Hilbe, R.; Schaefer, B.; Wagner, S.; Machleidt, F.; Garcia, C.; Ruwwe-Glösenkamp, C.; Lingscheid, T.; de Jarcy, L. B.; Stegemann, M. S.; Pfeiffer, M.; Jürgens, L.; Denker, S.; Zickler, D.; Spies, C.; Edel, A.; Müller, N. B.; Enghard, P.; Zelezniak, A.; Bellmann-Weiler, R.; Weiss, G.; Campbell, A.; Hayward, C.; Porteous, D. J.; Marioni, R. E.; Uhrig, A.; Zoller, H.; Löffler-Ragg, J.; Keller, M. A.; Tancevski, I.; Timms, J. F.; Zaikin, A.; Hippenstiel, S.; Ramharter, M.; Müller-Redetzky, H.; Witzenrath, M.; Suttorp, N.; Lilley, K.; Mülleder, M.; Sander, L. E.; group, P.-C.-S.; Kurth, F.; Ralser, M., A proteomic survival predictor for COVID-19 patients in intensive care. medRxiv 2021, 2021.06.24.21259374.

9. Ori, A.; Iskar, M.; Buczak, K.; Kastritis, P.; Parca, L.; Andres-Pons, A.; Singer, S.; Bork, P.; Beck, M., Spatiotemporal variation of mammalian protein complex stoichiometries. Genome Biol 2016, $17,47$.

10. Goh, W. W. B.; Wong, L., NetProt: Complex-based Feature Selection. J Proteome Res 2017, 16 (8), 3102-3112.

11. Goh, W. W., Fuzzy-FishNET: a highly reproducible protein complex-based approach for feature selection in comparative proteomics. BMC Med Genomics 2016, 9 (Suppl 3), 67.

12. Fossati, A.; Li, C.; Uliana, F.; Wendt, F.; Frommelt, F.; Sykacek, P.; Heusel, M.; Hallal, M.; Bludau, I.; Capraz, T.; Xue, P.; Song, J.; Wollscheid, B.; Purcell, A. W.; Gstaiger, M.; Aebersold, R., PCprophet: a framework for protein complex prediction and differential analysis using proteomic data. Nature Methods 2021.

13. Leake, M. C.; Chandler, J. H.; Wadhams, G. H.; Bai, F.; Berry, R. M.; Armitage, J. P., Stoichiometry and turnover in single, functioning membrane protein complexes. Nature 2006, 443 (7109), 355-8.

14. Wang, J.; Peng, X.; Peng, W.; Wu, F. X., Dynamic protein interaction network construction and applications. Proteomics 2014, 14 (4-5), 338-52.

15. Gordon, D. E.; Jang, G. M.; Bouhaddou, M.; Xu, J.; Obernier, K.; White, K. M.; O'Meara, M. J.; Rezelj, V. V.; Guo, J. Z.; Swaney, D. L.; Tummino, T. A.; Huttenhain, R.; Kaake, R. M.; Richards, A. L.; Tutuncuoglu, B.; Foussard, H.; Batra, J.; Haas, K.; Modak, M.; Kim, M.; Haas, P.; Polacco, B. J.; Braberg, H.; Fabius, J. M.; Eckhardt, M.; Soucheray, M.; Bennett, M. J.; Cakir, M.; McGregor, M. J.; Li, Q.; Meyer, B.; Roesch, F.; Vallet, T.; Mac Kain, A.; Miorin, L.; Moreno, E.; Naing, Z. Z. C.; Zhou, Y.; Peng, S.; Shi, Y.; Zhang, Z.; Shen, W.; Kirby, I. T.; Melnyk, J. E.; Chorba, J. S.; Lou, K.; Dai, S. A.; Barrio-Hernandez, I.; Memon, D.; 
Hernandez-Armenta, C.; Lyu, J.; Mathy, C. J. P.; Perica, T.; Pilla, K. B.; Ganesan, S. J.; Saltzberg, D. J.; Rakesh, R.; Liu, X.; Rosenthal, S. B.; Calviello, L.; Venkataramanan, S.; Liboy-Lugo, J.; Lin, Y.; Huang, X. P.; Liu, Y.; Wankowicz, S. A.; Bohn, M.; Safari, M.; Ugur, F. S.; Koh, C.; Savar, N. S.; Tran, Q. D.; Shengjuler, D.; Fletcher, S. J.; O'Neal, M. C.; Cai, Y.; Chang, J. C. J.; Broadhurst, D. J.; Klippsten, S.; Sharp, P. P.; Wenzell, N. A.; Kuzuoglu-Ozturk, D.; Wang, H. Y.; Trenker, R.; Young, J. M.; Cavero, D. A.; Hiatt, J.; Roth, T. L.; Rathore, U.; Subramanian, A.; Noack, J.; Hubert, M.; Stroud, R. M.; Frankel, A. D.; Rosenberg, O. S.; Verba, K. A.; Agard, D. A.; Ott, M.; Emerman, M.; Jura, N.; von Zastrow, M.; Verdin, E.; Ashworth, A.; Schwartz, O.; d'Enfert, C.; Mukherjee, S.; Jacobson, M.; Malik, H. S.; Fujimori, D. G.; Ideker, T.; Craik, C. S.; Floor, S. N.; Fraser, J. S.; Gross, J. D.; Sali, A.; Roth, B. L.; Ruggero, D.; Taunton, J.; Kortemme, T.; Beltrao, P.; Vignuzzi, M.; Garcia-Sastre, A.; Shokat, K. M.; Shoichet, B. K.; Krogan, N. J., A SARS-CoV-2 protein interaction map reveals targets for drug repurposing. Nature 2020, 583 (7816), 459-468.

16. Messner, C. B.; Demichev, V.; Wendisch, D.; Michalick, L.; White, M.; Freiwald, A.; Textoris-Taube, K.; Vernardis, S. I.; Egger, A. S.; Kreidl, M.; Ludwig, D.; Kilian, C.; Agostini, F.; Zelezniak, A.; Thibeault, C.; Pfeiffer, M.; Hippenstiel, S.; Hocke, A.; von Kalle, C.; Campbell, A.; Hayward, C.; Porteous, D. J.; Marioni, R. E.; Langenberg, C.; Lilley, K. S.; Kuebler, W. M.; Mulleder, M.; Drosten, C.; Suttorp, N.; Witzenrath, M.; Kurth, F.; Sander, L. E.; Ralser, M., Ultra-High-Throughput Clinical Proteomics Reveals Classifiers of COVID-19 Infection. Cell Syst 2020, 11 (1), 11-24 e4.

17. Ruepp, A.; Brauner, B.; Dunger-Kaltenbach, I.; Frishman, G.; Montrone, C.; Stransky, M.; Waegele, B.; Schmidt, T.; Doudieu, O. N.; Stumpflen, V.; Mewes, H. W., CORUM: the comprehensive resource of mammalian protein complexes. Nucleic Acids Res 2008, 36 (Database issue), D646-50.

18. Huttlin, E. L.; Ting, L.; Bruckner, R. J.; Gebreab, F.; Gygi, M. P.; Szpyt, J.; Tam, S.; Zarraga, G.; Colby, G.; Baltier, K.; Dong, R.; Guarani, V.; Vaites, L. P.; Ordureau, A.; Rad, R.; Erickson, B. K.; Wuhr, M.; Chick, J.; Zhai, B.; Kolippakkam, D.; Mintseris, J.; Obar, R. A.; Harris, T.; Artavanis-Tsakonas, S.; Sowa, M. E.; De Camilli, P.; Paulo, J. A.; Harper, J. W.; Gygi, S. P., The BioPlex Network: A Systematic Exploration of the Human Interactome. Cell 2015, 162 (2), 425-440.

19. Raudvere, U.; Kolberg, L.; Kuzmin, I.; Arak, T.; Adler, P.; Peterson, H.; Vilo, J., g:Profiler: a web server for functional enrichment analysis and conversions of gene lists (2019 update). Nucleic Acids Res 2019, 47(W1), W191-W198.

20. Mehta, P.; McAuley, D. F.; Brown, M.; Sanchez, E.; Tattersall, R. S.; Manson, J. J.; Hlh Across Speciality Collaboration, U. K., COVID-19: consider cytokine storm syndromes and immunosuppression. Lancet 2020, 395 (10229), 1033-1034.

21. Gabay, C.; Kushner, I., Acute-phase proteins and other systemic responses to inflammation. $N$ Engl J Med 1999, 340 (6), 448-54.

22. Polycarpou, A.; Howard, M.; Farrar, C. A.; Greenlaw, R.; Fanelli, G.; Wallis, R.; Klavinskis, L. S.; Sacks, S., Rationale for targeting complement in COVID-19. EMBO Mol Med 2020, 12 (8), e12642.

23. Georg, P.; Astaburuaga-Garcia, R.; Bonaguro, L.; Brumhard, S.; Michalick, L.; Lippert, L. J.; Kostevc, T.; Gabel, C.; Schneider, M.; Streitz, M.; Demichev, V.; Gemund, I.; Barone, M.; Tober-Lau, P.; Helbig, E. T.; Hillus, D.; Petrov, L.; Stein, J.; Dey, H. P.; Paclik, D.; Iwert, C.; Mulleder, M.; Aulakh, S. K.; Djudjaj, S.; 
Bulow, R. D.; Mei, H. E.; Schulz, A. R.; Thiel, A.; Hippenstiel, S.; Saliba, A. E.; Eils, R.; Lehmann, I.; Mall, M. A.; Stricker, S.; Rohmel, J.; Corman, V. M.; Beule, D.; Wyler, E.; Landthaler, M.; Obermayer, B.; von Stillfried, S.; Boor, P.; Demir, M.; Wesselmann, H.; Suttorp, N.; Uhrig, A.; Muller-Redetzky, H.; Nattermann, J.; Kuebler, W. M.; Meisel, C.; Ralser, M.; Schultze, J. L.; Aschenbrenner, A. C.; Thibeault, C.; Kurth, F.; Sander, L. E.; Bluthgen, N.; Sawitzki, B.; Group, P.-C.-S., Complement activation induces excessive T cell cytotoxicity in severe COVID-19. Cell 2021.

24. Nie, X.; Qian, L.; Sun, R.; Huang, B.; Dong, X.; Xiao, Q.; Zhang, Q.; Lu, T.; Yue, L.; Chen, S.; Li, X.; Sun, Y.; Li, L.; Xu, L.; Li, Y.; Yang, M.; Xue, Z.; Liang, S.; Ding, X.; Yuan, C.; Peng, L.; Liu, W.; Yi, X.; Lyu, M.; Xiao, G.; Xu, X.; Ge, W.; He, J.; Fan, J.; Wu, J.; Luo, M.; Chang, X.; Pan, H.; Cai, X.; Zhou, J.; Yu, J.; Gao, H.; Xie, M.; Wang, S.; Ruan, G.; Chen, H.; Su, H.; Mei, H.; Luo, D.; Zhao, D.; Xu, F.; Li, Y.; Zhu, Y.; Xia, J.; Hu, Y.; Guo, T., Multi-organ proteomic landscape of COVID-19 autopsies. Cell 2021, 184 (3), 775-791 e14.

25. Wang, C.; Xie, J.; Zhao, L.; Fei, X.; Zhang, H.; Tan, Y.; Nie, X.; Zhou, L.; Liu, Z.; Ren, Y.; Yuan, L.; Zhang, Y.; Zhang, J.; Liang, L.; Chen, X.; Liu, X.; Wang, P.; Han, X.; Weng, X.; Chen, Y.; Yu, T.; Zhang, X.; Cai, J.; Chen, R.; Shi, Z. L.; Bian, X. W., Alveolar macrophage dysfunction and cytokine storm in the pathogenesis of two severe COVID-19 patients. EBioMedicine 2020, 57, 102833.

26. Vollmy, F.; van den Toorn, H.; Zenezini Chiozzi, R.; Zucchetti, O.; Papi, A.; Volta, C. A.; Marracino, L.; Vieceli Dalla Sega, F.; Fortini, F.; Demichev, V.; Tober-Lau, P.; Campo, G.; Contoli, M.; Ralser, M.; Kurth, F.; Spadaro, S.; Rizzo, P.; Heck, A. J., A serum proteome signature to predict mortality in severe COVID-19 patients. Life Sci Alliance 2021, 4 (9).

27. Geyer, P. E.; Arend, F. M.; Doll, S.; Louiset, M. L.; Virreira Winter, S.; Muller-Reif, J. B.; Torun, F. M.; Weigand, M.; Eichhorn, P.; Bruegel, M.; Strauss, M. T.; Holdt, L. M.; Mann, M.; Teupser, D., Highresolution serum proteome trajectories in COVID-19 reveal patient-specific seroconversion. EMBO Mol Med 2021, 13 (8), e14167.

28. Chevrier, S.; Zurbuchen, Y.; Cervia, C.; Adamo, S.; Raeber, M. E.; de Souza, N.; Sivapatham, S.; Jacobs, A.; Bachli, E.; Rudiger, A.; Stussi-Helbling, M.; Huber, L. C.; Schaer, D. J.; Nilsson, J.; Boyman, O.; Bodenmiller, B., A distinct innate immune signature marks progression from mild to severe COVID-19. Cell Rep Med 2021, 2 (1), 100166.

29. Altay, O.; Arif, M.; Li, X.; Yang, H.; Aydin, M.; Alkurt, G.; Kim, W.; Akyol, D.; Zhang, C.; Dinler-Doganay, G.; Turkez, H.; Shoaie, S.; Nielsen, J.; Boren, J.; Olmuscelik, O.; Doganay, L.; Uhlen, M.; Mardinoglu, A., Combined Metabolic Activators Accelerates Recovery in Mild-to-Moderate COVID-19. Adv Sci (Weinh) 2021, 8 (17), e2101222.

30. D'Alessandro, A.; Thomas, T.; Dzieciatkowska, M.; Hill, R. C.; Francis, R. O.; Hudson, K. E.; Zimring, J. C.; Hod, E. A.; Spitalnik, S. L.; Hansen, K. C., Serum Proteomics in COVID-19 Patients: Altered Coagulation and Complement Status as a Function of IL-6 Level. J Proteome Res 2020, 19 (11), 4417-4427.

31. Zhong, W.; Altay, O.; Arif, M.; Edfors, F.; Doganay, L.; Mardinoglu, A.; Uhlen, M.; Fagerberg, L., Next generation plasma proteome profiling of COVID-19 patients with mild to moderate symptoms. EBioMedicine 2021, 74, 103723. 
32. Su, Y.; Chen, D.; Yuan, D.; Lausted, C.; Choi, J.; Dai, C. L.; Voillet, V.; Duvvuri, V. R.; Scherler, K.; Troisch, P.; Baloni, P.; Qin, G.; Smith, B.; Kornilov, S. A.; Rostomily, C.; Xu, A.; Li, J.; Dong, S.; Rothchild, A.; Zhou, J.; Murray, K.; Edmark, R.; Hong, S.; Heath, J. E.; Earls, J.; Zhang, R.; Xie, J.; Li, S.; Roper, R.; Jones, L.; Zhou, Y.; Rowen, L.; Liu, R.; Mackay, S.; O'Mahony, D. S.; Dale, C. R.; Wallick, J. A.; Algren, H. A.; Zager, M. A.; Unit, I. S.-S. C. B.; Wei, W.; Price, N. D.; Huang, S.; Subramanian, N.; Wang, K.; Magis, A. T.; Hadlock, J. J.; Hood, L.; Aderem, A.; Bluestone, J. A.; Lanier, L. L.; Greenberg, P. D.; Gottardo, R.; Davis, M. M.; Goldman, J. D.; Heath, J. R., Multi-Omics Resolves a Sharp Disease-State Shift between Mild and Moderate COVID-19. Cell 2020, 183 (6), 1479-1495 e20.

33. Zhou, S.; Butler-Laporte, G.; Nakanishi, T.; Morrison, D. R.; Afilalo, J.; Afilalo, M.; Laurent, L.; Pietzner, M.; Kerrison, N.; Zhao, K.; Brunet-Ratnasingham, E.; Henry, D.; Kimchi, N.; Afrasiabi, Z.; Rezk, N.; Bouab, M.; Petitjean, L.; Guzman, C.; Xue, X.; Tselios, C.; Vulesevic, B.; Adeleye, O.; Abdullah, T.; Almamlouk, N.; Chen, Y.; Chasse, M.; Durand, M.; Paterson, C.; Normark, J.; Frithiof, R.; Lipcsey, M.; Hultstrom, M.; Greenwood, C. M. T.; Zeberg, H.; Langenberg, C.; Thysell, E.; Pollak, M.; Mooser, V.; Forgetta, V.; Kaufmann, D. E.; Richards, J. B., A Neanderthal OAS1 isoform protects individuals of European ancestry against COVID-19 susceptibility and severity. Nat Med 2021, 27 (4), 659-667.

34. Shah, A. B.; DiMartino, S. J.; Trujillo, G.; Kew, R. R., Selective inhibition of the C5a chemotactic cofactor function of the vitamin D binding protein by 1,25(OH)2 vitamin D3. Mol Immunol 2006, 43 (8), 1109-15.

35. El-Amraoui, A.; Schonn, J. S.; Kussel-Andermann, P.; Blanchard, S.; Desnos, C.; Henry, J. P.; Wolfrum, U.; Darchen, F.; Petit, C., MyRIP, a novel Rab effector, enables myosin VIla recruitment to retinal melanosomes. EMBO Rep 2002, 3 (5), 463-70.

36. Lu, C.; Hou, N., Skin Hyperpigmentation in Coronavirus Disease 2019 Patients: Is Polymyxin B the Culprit? Front Pharmacol 2020, 11, 01304.

37. Myron Johnson, A.; Merlini, G.; Sheldon, J.; Ichihara, K.; Scientific Division Committee on Plasma Proteins, I. F. o. C. C.; Laboratory, M., Clinical indications for plasma protein assays: transthyretin (prealbumin) in inflammation and malnutrition. Clin Chem Lab Med 2007, 45(3), 419-26.

38. Rubin, L. P.; Ross, A. C.; Stephensen, C. B.; Bohn, T.; Tanumihardjo, S. A., Metabolic Effects of Inflammation on Vitamin A and Carotenoids in Humans and Animal Models. Adv Nutr 2017, 8 (2), 197-212.

39. Marcos-Jimenez, A.; Sanchez-Alonso, S.; Alcaraz-Serna, A.; Esparcia, L.; Lopez-Sanz, C.; SampedroNunez, M.; Mateu-Albero, T.; Sanchez-Cerrillo, I.; Martinez-Fleta, P.; Gabrie, L.; Del Campo Guerola, L.; Rodriguez-Frade, J. M.; Casasnovas, J. M.; Reyburn, H. T.; Vales-Gomez, M.; Lopez-Trascasa, M.; Martin-Gayo, E.; Calzada, M. J.; Castaneda, S.; de la Fuente, H.; Gonzalez-Alvaro, I.; Sanchez-Madrid, F.; Munoz-Calleja, C.; Alfranca, A., Deregulated cellular circuits driving immunoglobulins and complement consumption associate with the severity of COVID-19 patients. Eur J Immuno/ 2021, 51 (3), 634-647.

40. Carvelli, J.; Demaria, O.; Vely, F.; Batista, L.; Chouaki Benmansour, N.; Fares, J.; Carpentier, S.; Thibult, M. L.; Morel, A.; Remark, R.; Andre, P.; Represa, A.; Piperoglou, C.; Explore, C.-I. P. H. g.; Explore, C.-M. I. g.; Cordier, P. Y.; Le Dault, E.; Guervilly, C.; Simeone, P.; Gainnier, M.; Morel, Y.; Ebbo, M.; Schleinitz, N.; 
Vivier, E., Association of COVID-19 inflammation with activation of the C5a-C5aR1 axis. Nature 2020, 588 (7836), 146-150.

41. Zhao, P.; Wu, J.; Lu, F.; Peng, X.; Liu, C.; Zhou, N.; Ying, M., The imbalance in the complement system and its possible physiological mechanisms in patients with lung cancer. BMC Cancer 2019, 19 (1), 201.

42. Zhao, J.; Wang, B.; Yu, H.; Wang, Y.; Liu, X.; Zhang, Q., tdrd1 is a germline-specific and sexually dimorphically expressed gene in Paralichthys olivaceus. Gene 2018, 673, 61-69.

43. Bergmann, C. C.; Lane, T. E.; Stohlman, S. A., Coronavirus infection of the central nervous system: host-virus stand-off. Nat Rev Microbiol 2006, 4 (2), 121-32.

44. Ciavarella, C.; Motta, I.; Valente, S.; Pasquinelli, G., Pharmacological (or Synthetic) and Nutritional Agonists of PPAR-gamma as Candidates for Cytokine Storm Modulation in COVID-19 Disease. Molecules 2020, $25(9)$.

45. Taghizadeh, S.; Vazehan, R.; Beheshtian, M.; Sadeghinia, F.; Fattahi, Z.; Mohseni, M.; Arzhangi, S.; Nafissi, S.; Kariminejad, A.; Najmabadi, H.; Kahrizi, K., Molecular Diagnosis of Hereditary Neuropathies by Whole Exome Sequencing and Expanding the Phenotype Spectrum. Arch Iran Med 2020, 23 (7), 426-433.

46. Lefranc, M. P., Immunoglobulin and T Cell Receptor Genes: IMGT((R)) and the Birth and Rise of Immunoinformatics. Front Immuno/ 2014, 5, 22.

47. Sirwi, A.; Hussain, M. M., Lipid transfer proteins in the assembly of apoB-containing lipoproteins. $J$ Lipid Res 2018, 59 (7), 1094-1102.

48. Cater, J. H.; Wilson, M. R.; Wyatt, A. R., Alpha-2-Macroglobulin, a Hypochlorite-Regulated Chaperone and Immune System Modulator. Oxid Med Cell Longev 2019, 2019, 5410657.

49. Chen, K. L.; Li, L.; Li, C. M.; Wang, Y. R.; Yang, F. X.; Kuang, M. Q.; Wang, G. L., SIRT7 Regulates Lipopolysaccharide-Induced Inflammatory Injury by Suppressing the NF-kappaB Signaling Pathway. Oxid Med Cell Longev 2019,2019, 3187972.

\section{Tables}

Table 1. Information of $\mathbf{4 0}$ patients in the training set and all total patients. 


$\begin{array}{clllll}\text { Study } & \text { Study } & \begin{array}{l}\text { Study } \\ \text { severe }\end{array} & \text { All } & \text { All } & \text { All } \\ \text { total } & \text { non } & \text { total } & \text { non severe } & \text { severe } \\ (40) & \text { severe } & (15) & (108) & (36)\end{array}$

\begin{tabular}{|c|c|c|c|c|c|c|}
\hline $\begin{array}{l}\text { Sex } \\
\text { (male/female) }\end{array}$ & $17 / 23$ & $8 / 17$ & $9 / 6$ & $77 / 67$ & $57 / 51$ & $20 / 16$ \\
\hline Age & $51.1 \pm 17.3$ & $48 \pm 18.9$ & $56.3 \pm 13.1$ & $47.6 \pm 14.6$ & $45 \pm 14.2$ & $55.5 \pm 12.8^{\# \#}$ \\
\hline BMI & $23.9 \pm 3.3$ & $22.7 \pm 3.2$ & $26.1 \pm 2.1^{\star \star}$ & $24.2 \pm 3.1$ & $23.9 \pm 3.2$ & $25.5 \pm 2.3^{\# \#}$ \\
\hline Onset admission & $7.5 \pm 4.4$ & $7.5 \pm 4.7$ & $7.4 \pm 4.1$ & $7 \pm 4.2$ & $6.8 \pm 3.9$ & $7.9 \pm 4.9$ \\
\hline $\begin{array}{l}\text { Admission } \\
\text { discharge }\end{array}$ & $27.5 \pm 8.9$ & $27.6 \pm 10$ & $27.2 \pm 7$ & $21.6 \pm 9.4$ & $20.5 \pm 9.7$ & $24.7 \pm 7.8^{\#}$ \\
\hline \multicolumn{7}{|l|}{ Symptoms (\%) } \\
\hline Fever & $27(67)$ & $12(48)$ & $15(100)^{* *}$ & $\begin{array}{l}104 \\
(72.2)\end{array}$ & $70(64.8)$ & $34(94.4)^{\# \#}$ \\
\hline Pharyngalgia & $6(15)$ & $5(20)$ & $1(6.7)$ & $17(11.8)$ & 15(13.9) & $2(5.6)$ \\
\hline Cough & $18(45)$ & $12(48)$ & $6(40)$ & $65(45.1)$ & $47(43.5)$ & $18(50)$ \\
\hline Expectoration & $10(25)$ & $7(28)$ & $3(20)$ & $26(18.1)$ & 19(17.6) & $7(19.4)$ \\
\hline Fatigue & $2(5)$ & $1(4)$ & $1(6.7)$ & $16(11.1)$ & $10(9.3)$ & $6(16.7)$ \\
\hline Headache & $4(10)$ & $2(8)$ & $2(13.3)$ & $16(11.1)$ & $9(8.3)$ & $7(19.4)$ \\
\hline Diarrhea & $1(2.5)$ & $0(0)$ & $1(6.7)$ & $6(4.2)$ & $3(2.8)$ & $3(8.3)$ \\
\hline Chest tightness & $4(10)$ & $2(8)$ & $2(13.3)$ & $11(7.6)$ & $7(6.5)$ & $4(11.1)$ \\
\hline \multicolumn{7}{|l|}{ Comorbidity (\%) } \\
\hline Hypertension & $8(20)$ & $4(16)$ & $4(26.7)$ & $22(15.3)$ & $14(13)$ & $8(22.2)$ \\
\hline Diabetes & $6(15)$ & $2(8)$ & $4(26.7)$ & $14(9.7)$ & $9(8.3)$ & $5(13.9)$ \\
\hline Hyperlipidemia & $2(5)$ & $1(4)$ & $1(6.7)$ & $3(2.1)$ & $2(1.9)$ & $1(2.8)$ \\
\hline $\begin{array}{l}\text { Cardiovascular } \\
\text { disease }\end{array}$ & $1(2.5)$ & $0(0)$ & $1(6.7)$ & $3(2.1)$ & $1(0.9)$ & $2(5.6)$ \\
\hline Kidney disease & $1(2.5)$ & $0(0)$ & $1(6.7)$ & $2(1.4)$ & $1(0.9)$ & $1(2.8)$ \\
\hline Digestive system & $3(7.5)$ & $2(8)$ & $1(6.7)$ & $7(4.9)$ & $6(5.6)$ & $1(2.8)$ \\
\hline
\end{tabular}

${ }^{\star *} P<0.01$, study severe vs study non severe; ${ }^{\#} P<0.05,{ }^{\# \#} P<0.01$, all severe vs all non-severe. 
Table 2. Summary of the dataset used for this study.

\begin{tabular}{llllll} 
& Patients (non-severe/severe) & Samples & MS Method & Proteins & Missing (\%) \\
\hline Training & $40(25 / 15)$ & 54 & 45 min SWATH & 331 & 21.7 \\
\hline Test 1 & $21(6 / 15)$ & 21 & TMTpro 16plex & 894 & 35.5 \\
\hline Test 2 & $31(12 / 19)$ & 102 & 5min SWATH & 222 & 12.2
\end{tabular}

\section{Figures}

\section{Figure 1}

Study overview. In general, 331 proteins were identified from 54 serum samples of COVID-19 patients. Subsequently, five kinds of 868 features were derived from these proteins. The top 25 differential features were selected for the machine learning model, which was further validated in two test datasets.

\section{Figure 2}

The selected features for classifying COVID-19. (A) All Identified features ranked by log $p$ value; (B) The top 25 features identified; (C) The heatmap of top 25 features in the training set.

\section{Figure 3}

The performance of the machine learning model. (A) The PCA map of the training set and test sets using all features; (B) The comparison of AUC between the model with five types of features and the model with only one type of feature in the training set, test set 1 , and the test set 2.

\section{Figure 4}

The biological interpretation of the top 25 features. MAC, membrane attack complex. Red border, upregulation; green boarder, downregulation.

\section{Supplementary Files}


This is a list of supplementary files associated with this preprint. Click to download.

- FigureS1.pdf

- SupplementaryTableS1.docx

- Tables2.csv

- TableS3.xlsx

- Tables4.csv 